\title{
Литература
}

1. Гамезо М.В., Домашенко И.А. Атлас по психологии: Информ.метод. Пособие к курсу «Психология человека»: - М.: Пед. общ-во России, 1999. - 397 c.

2. Ленглер О. А. Субъектность человека: психолого-педагогические основы [Текст] / О. А. Ленглер // Молодой ученый. — 2012. — №11. — С. 440442.

3. Петровский А.В., Ярошевский М.Г. Психология. Учеб.для вузов. М.: Издат. Центр «Академия», 2000. -512 с.

4. Попов Л.М. Психологический механизм и зоны развития субъекта / Л.М.Попов // Субъектный подход в инновационной подготовке педагогапсихолога. Под ред. Ф.Г.Мухаметзяновой. - Казань: ЮЛАКС, 2006. - С. 21-33.

5. $\quad$ Психология прогнозирования: успехи в познании будущего. - СПб.: Речь,2003. - 352 с.

\section{ИССЛЕДОВАНИЕ СТРУКТУРЫ ЖИЗНЕННОГО ПРОСТРАНСТВА ЛИЧНОСТИ}

Проскурякова Е.А.

Аннотация: Субъективное ощущение жизненного пространства личности является одной из важных составляющих самоощущения человека, влияющего на уровень самооценки, настроение, мотивационно-регулятивную функцию и другие основные параметрические характеристики личности. Данное исследование призвано рассмотреть факторы, влияющие на удовлетворенность личности ее жизненным пространством и отношение к нему в целом. В соответствии с нашей гипотезой, к этим факторам относятся такие личностные свойства, как психологическое благополучие, суверенность психологического пространства и смысложизненные ориентации.

Удовлетворенность местом проживания и своим жизненным пространством в целом одна из основных составляющих человеческого самоощущения. Субъективное ощущение удовлетворенности жизнью прямо влияет на мотивацию, настроение человека и его жизнедеятельность.

Тема отношения к жизненному пространству является актуальной, поскольку позволяет приблизиться к пониманию современного человека как субъекта и автора своего мира, создателя своего жизненного пространства, дает возможность проанализировать взаимоотношения личности и среды с различных сторон.

Жизненное пространство личности - это все, что нас окружает. Это “человек и психологическая среда, как она существует для него" [2, с. 77] по определению К. Левина - одного из ключевых исследователей жизненного пространства, а также автора теории поля, показывающей взаимоотношения человека с окружающей его средой и акцентирующей внимание именно на моменте взаимодействия, важности изучения человека в ситуации, а не отдельно от нее. 
В настоящее время человек перестал считаться набором личностных свойств и совокупностью измеряемых параметров. Самыми актуальными исследованиями на данный момент представляются работы, рассматривающие реакцию человека на современные вызовы его жизненной ситуации, качественно отличающейся от ситуации прошлых столетий [3]. И, конечно, возникает необходимость изучить человека в его новой жизненной ситуации, рассмотреть его реакции на необходимость осуществлять экзистенциальный выбор, что и может осуществить психологическая наука.

Объектом нашего исследования выступает личность в контексте своего бытия, предмет исследования - структура жизненного пространства личности. В конечном итоге мы хотим подтвердить или опровергнуть гипотезу о том, что на отношение к жизненному пространству личности напрямую влияет выраженность таких личностных свойств, как суверенность психологического пространства, смысложизненные ориентации и психологическое благополучие.

Н.А. Кондратова под руководством Д.А. Леонтьева разработала концепцию психологического образа жизненного пространства личности, в которую было включено 2 уровня: территориально-пространственный и уровень идеальных объектов. Данная схема была создана после анализа эссе на тему жизненного пространства лицеистами (12-14 лет) и студентами (18-20 лет).

Мы повторили эксперимент Наталии Александровны для подтверждения теоретической модели на людях более старшего возраста. В целом, большинство гипотез Н.А. Кондратовой подтвердилось и со многими положениями мы согласны. Но некоторые пункты подверглись трансформации.

В нашем представлении модель образа жизненного пространства личности человека малой и средней взрослости выглядит следующим образом: его структурными элементами предстают территориально-пространственный уровень (остался без изменений), смысловой уровень (предыдущее название уровень идеальных объектов) и личностный уровень. Существование и важность территориально-пространственного уровня в рамках разговора о пространстве сложно отрицать - представляется очевидным факт, что они связаны напрямую. Смысловой уровень был переименован из уровня идеальных объектов, поскольку подчеркивает важность принадлежности смысла месту, важность персонализированности смысла. И, наконец, был добавлен личностный уровень, поскольку люди и общение с ними занимают достаточно большую часть жизненного пространства личности, но отнести их как к первому, так и ко второму уровню проблематично - они представляются обособленным и специфическим конструктом.

Идея привнесения личностного конструкта заложена уже в работе Кондратовой. При анализе исходных данных выявлено 5 опорных пунктов, характеризующих элементы жизненного пространства: “1) люди; 2) конкретные материальные объекты (предметы, «места», явления природы); 3) дела, занятия, связанные с этими материальными объектами, общение с людьми; 4) элементы внутреннего мира, характеристики собственной личности и жизненной ситуации субъекта; 5) идеальные объекты (уникальные смысловые комплексы)" 
[1, с. 141]. Именно они впоследствии объединяются в вышеозвученные две категории. Проведя собственное исследование и обратив внимание на 5 исходных пунктов, мы решили в конечном итоге выделить именно 3 основания: территориальное, смысловое и личностное.

Возвращаясь к описанию гипотез, можно описать дополнительные исследовательские предположения, опираясь на представленную модель образа жизненного пространства личности. Итак, отношение к жизненному пространству детерминировано определенными личностными свойствами, а именно: территориально-пространственный уровень обусловлен степенью проявленности суверенности психологического пространства, смысловой уровень зависит от качества смысложизненных ориентаций, а личностный уровень строится на степени выраженности психологического благополучия личности. Данную гипотезу мы планируем подтвердить посредством основного эксперимента, а на данный момент представим результаты пилотного.

Мы постарались соблюсти процедуру обработки исследователей, чтобы результаты считались сопоставимыми. Но также в соответствии с задачами, мы внесли некоторые корректировки.

В собранных эссе в первоначальном эксперименте выделялись такие категории: “люди, жилое пространство, учеба, город, деятельность, информация, природа, я сам, идеальные объекты, другое” [1, с. 108]. При обработке была изменена категория "учеба" на "места деятельности", включающую места учебы и работы, а также другой основной занятости. Данная модернизация была нужна, поскольку в оригинальном эксперименте принимали участие лицеисты и студенты, основной деятельностью которых была учебная. В нашем эксперименте участвовали респонденты ранней и средней взрослости, основной деятельностью последних стоит считать работу. Также была убрана категория "другое", затрудняющая обработку данных и не имеющая особой необходимости.

При сопоставлении полученных данных с первоначальным экспериментом были получены следующие результаты. Во-первых, с возрастом увеличивается количество используемых единиц анализа в эссе (у Кондратовой - 13,1, в нашем случае среднее количество смысловых единиц в одной работе - 59). Этот факт был обозначен у Кондратовой, так и замечен нами, но мы не можем его значимо подтвердить с помощью инструментов статистической обработки из-за малого количества людей разных возрастных категорий. Тем не менее, мы можем говорить о проявлении тенденции: по мере взросления и социализации личности расширяются сферы деятельности, число социальных связей, что проявляется большим количеством единиц анализа в полученных эссе, поскольку взрослые люди могут воспринять и проанализировать большее число категорий пространства, чем подростки и студенты. Получается, задействуется больше микро пространств в сфере жизненного пространства личности: ограниченные в пространстве подростки расширяют его с возрастом в юности и ранней взрослости в зависимости от своих нужд интенсивным и экстенсивным способами. 
Во-вторых, самая часто встречающаяся категория в изначальном эксперименте была "люди" $(0,35)$, в нашем - "я сам" (частота встречаемости - 0, 38). В этом случае можно говорить о том, что обе категории относятся к личностному уровню, а также о том, что с увеличением как возраста, так и уровня образования увеличивается способность к рефлексии и желание ей заниматься.

В-третьих, каждый испытуемый представил в эссе все 3 уровня, но в большей степени концентрировался только на одном. Данное обстоятельство напоминает механизм выделения ценностных ориентаций: у одного человека не может быть множество главных ценностей, необходимо выбирать и ранжировать.

В-четвертых, самый часто выражаемый уровень - личностный, что дополнительно подкрепляет необходимость выделения данного уровня, а также показывает сопоставимость с данными Кондратовой в случае частоты упоминания категории “люди".

В-пятых, большинство людей (62,5\% из опрошенных) довольны своим жизненным пространством, но желают изменить его, внести корректировки, верят, что жизненное пространство не бывает стабильным и является изменчивой структурой, что не совсем соотносится с результатами оригинального эксперимента: в нем были проявлены, в основном, полярные мнения (либо доволен полностью пространством, либо хочу изменить его). Данное обстоятельство также можно обосновать возрастными особенностями: с увеличением жизненного опыта модель окружающего мира из полярной трансформируется в многомерную.

Жизненный мир человека с возрастом усложняется многократно. Мы получили данные о том, что количество смысловых единиц анализа увеличивается с возрастом, что говорит об усложнении жизненного пространства, наличии большего количества микро пространств, а также в совокупности с рефлексивным характером эссе, с наличием множества абстрактных категорий в работах людей ранней и средней взрослости можно говорить о сложной организации жизненного пространства, его концентрированной насыщенности с увеличением возраста, выделении особенной ориентированности, сосредоточенности на определенном структурном направлении (территориальном, личностном и смысловом) и увеличении значимости своей личности, центрации на ней и своих ощущений. Данное исследование дало возможность окунуться в представления о жизненном пространстве личности. Показано, что большинство респондентов довольны своим жизненным пространством, но при этом хотят его изменять и совершенствовать, что подтверждает понимание жизненного пространства личности как постоянно динамически изменяющегося психологического феномена.

\section{Литература}

1. Кондратова Н.А. Субъективная репрезентация жизненного пространства личности. Диссертация на соискание ученой степени кандидата наук под рук. Д.А. Леонтьева, М.: МГУ им. М.В. Ломоносова, 2009. - 246 с. 
2. Левин К. Теория поля в социальных науках / К. Левин. - СПб.: Сенсор, 2000. $-368 \mathrm{c}$.

3. Психологические исследования личности: история, современное состояние, перспективы / Отв. ред. М.И. Воловикова, А.Л. Журавлев, Н.Е. Харламенкова. - М.: изд-во “Институт психологии РАН", 2016. - 448 с. (Труды Института психологии РАН).

\section{СОВМЕСТНОЕ ВЛИЯНИЕ СЕМЕЙНОГО ПОЛОЖЕНИЯ, СТАЖА СУПРУЖЕСКИХ ОТНОШЕНИЙ И СТАТУСА ЖЕНЩИН НА ПОКАЗАТЕЛИ УРОВНЯ СУБЬЕКТИВНОГО КОНТРОЛЯ*}

Радостева А.Г.

В современной психологии одним из активно развивающихся направлений является психология материнства. В рамках данного направления рассматривается достаточно большой круг вопросов: психологическая готовность женщины к материнству $[1,3,6]$; факторы, влияющие на развитие материнской сферы в структуре личности женщин [8]; изучение психологического состояния беременны женщин [2,3] при нормальной и осложненной патологиями беременности [7,5,9]

Работы, посвященные изучению материнства, демонстрируют, что исследование данного феномена возможно у женщин, ещё не имеющих детей, как этапа прогнозирования будущего материнства; у беременных женщин, как периода становления образа матери и начала реализации родительских установок; у женщин, имеющих детей, как фиксирование складывающегося образа материнства.

Материнство непосредственно связано с готовностью женщины к рождению ребёнка, которая в свою очередь, включает в себя внутреннюю работу, связанную с осознанием своих жизненных задач, готовностью к изменениям структуры семьи и освоению новой социальной роли, а также ответственности и принятию многочисленных обязанностей матери.

Исследования Ю.В. Ковалёвой и Е.А. Сергиенко свидетельствуют, что неосознаваемые представления о материнстве основываются на личностных качествах женщин, их раннем семейном опыте, а также на готовности женщины к специфическому материнскому поведению. Авторы также отмечают, что особенно важным является способность регулировать поведение без излишних усилий и конфликтных переживаний на уровне Я [4].

Отсюда становится очевидной необходимость диагностирования уровня субъективного контроля (уровня интернальности) женщин, сообщающего о способности испытуемых контролировать значимые события своей жизни, быть их автором и причиной, нести ответственность за происходящие с ними события, a не искать объяснения в действиях других людей или обстоятельствах.

Немаловажным фактором в формировании интернальности и придания уверенности в собственных возможностях является семейное положение женщины. 